Pacific Journal of Mathematic 


\title{
ON PARTIAL HOMOMORPHISMS OF SEMIGROUPS
}

\author{
B. D. ARENdt AND C. J. Stuth
}

Let $S$ be a semigroup and $T$ be a semigroup with zero $\left(T=T^{0}\right)$. An ideal extension of $S$ by $T$ is a semigroup $V$ containing $S$ as an ideal and such that the Rees quotient $V / S$ is isomorphic to $T$. A mapping $\alpha$ from $T^{*}=T-\{0\}$ into $S$ is said to be a partial homomorphism, if $t_{1}, t_{2} \in T^{*}, t_{1} t_{2} \neq 0$ implies $\left(t_{1} t_{2}\right) \alpha=\left(t_{1} \alpha\right)\left(t_{2} \alpha\right)$. Every partial homomorphism from $T^{*}$ into $S$ gives rise to an ideal extension of $S$ by $T$. Further, in certain cases every ideal extension of $S$ by $T$ is obtained in this way. In this paper a characterization is given for all partial homomorphisms from $T^{*}$ into $S$.

It is not known in general when all extensions of $S$ by $T$ are determined by the partial homomorphisms of $T^{*}$ into $S$. Clifford has shown this to be the case when $S$ has an identity (see [2, §4.4]). Further results in this direction have been obtained by Warne [4] and Petrich [3]. The partial homomorphisms of a completely 0 -simple semigroup into an arbitrary semigroup have been determined by Clifford [1].

An element $x$ of a semigroup $S$ is said to be prime if $x$ does not belong to $S^{2}$. $S$ is said to have unique factorization if every nonzero element of $S$ can be written uniquely as a product of powers of primes. Of course, if $S$ is not commutative, we must take the order of the factors into account. We define the kernel of a homomorphism into a semigroup with zero to be the complete inverse image of zero.

THEOREM 1. A [commutative] semigroup $S$ has unique factorization if and only if $S$ is free [commutative] or the Rees quotient of a free [commutative] semigroup.

Proof. Suppose $S$ has unique factorization, and let $X$ be the set of primes of $S$. If $0 \notin S$, then clearly $S$ is free [commutative] on $X$. So assume $0 \in S$, and let $F_{X}$ be the free [commutative] semigroup on $X$ with homomorphism $\phi$ from $F_{X}$ onto $S$ such that $x \phi=x$ for all $x \in X$ [2, p. 41]. Let $K$ be the kernel of $\phi$. Since $S$ has unique factorization, $\phi$ must be one-to-one on $F_{X}-K$, so $S$ is isomorphic to the Rees quotient $F_{X} / K$. The converse is obvious.

CoRollary 2. If $S=S^{0}$, then there exists a semigroup $U$ with unique factorization and a homomorphism from $U$ onto $S$ with trivial kernel. 
Proof. There exists a free semigroup $F$ which is homomorphic onto $S$ with kernel $K$. Set $U=F / K$ and use Theorem 1.6 of [2].

THEOREM 3. Let $U$ be a semigroup with unique factorization and let $X$ be the set of primes of $U$. Let $S$ be any semigroup. Then any mapping $\alpha$ from $X$ into $S$ can be extended to a partial homomorphism of $U^{*}$ into $S$.

\section{Proof. Omitted.}

We denote by $\pi_{\alpha}$ the equivalence relation induced by a mapping $\alpha$ on its domain and use $\leqq$ for the usual partial ordering of relations on a set.

Theorem 4. Let $T=T^{0}$ and $S$ be semigroups. By Corollary 2 there exists a semigroup $U$ with unique factorization and a homomorphism $\phi$ from $U$ onto $T$ with trivial kernel. Let $\alpha$ be any partial homomorphism from $U^{*}$ into $S$ such that $\pi_{\dot{\phi}} \leqq \pi_{\alpha}$ on $U^{*}$ and define $\alpha^{\prime}: T^{*} \rightarrow S$ as follows. If $y \in T^{*}$ then there exists an $x \in U^{*}$ such that $y=x \phi$ and we define $y \alpha^{\prime}=x \alpha$. Then $\alpha^{\prime}$ is a partial homomorphism from $T^{*}$ into $S$. Conversely every partial homomorphism of $T^{*}$ into $S$ is determined in this manner. Finally, the mapping $\alpha \rightarrow \alpha^{\prime}$ is one-to-one.

Proof. $\alpha^{\prime}$ is well defined since $\pi_{\dot{\phi}} \leqq \pi_{\alpha}$ on $U^{*}$, and it is a partial homomorphism since $\alpha$ is. Conversely, if $\alpha^{\prime}$ is a partial homomorphism from $T^{*}$ into $S$, then define $x \alpha=x \phi \alpha^{\prime}$ for $x \in U^{*}$. If $x_{1}, x_{2} \in U^{*}$ with $x_{1} x_{2} \neq 0$, then $\left(x_{1} x_{2}\right) \dot{\rho} \alpha^{\prime}=\left(\left(x_{1} \phi\right)\left(x_{2} \rho\right)\right) \alpha^{\prime}$ and this in turn is equal to $\left(x_{1} \phi \alpha^{\prime}\right)\left(x_{2} \phi \alpha^{\prime}\right)$ since $\phi$ has trivial kernel. Thus $\alpha$ is a partial homomorphism from $U^{*}$ into $S$ such that $\pi_{\phi} \leqq \pi_{\alpha}$ on $U^{*}$.

Now let $\alpha, \beta$ be partial homomorphisms from $U^{*}$ into $S$ such that $\pi_{\dot{\phi}} \leqq \pi_{\alpha}, \pi_{\dot{\phi}} \leqq \pi_{\beta}$ on $U^{*}$ and $\alpha^{\prime}=\beta^{\prime}$. Thus for all $x \in U^{*}$, $x \dot{\phi} \alpha^{\prime}=x \dot{\phi} \beta^{\prime} \Rightarrow x \alpha=x \beta$ so $\alpha=\beta$ and the mapping is one-to-one.

\section{BIBLIOGRAPHY}

1. A. H. Clifford, Partial homomorphic images of Brandt groupoids, Proc. Amer. Math. Soc. 16 (1965), 538-544.

2. A. H. Clifford and G. B. Preston, Algebraic theory of semigroups, vol. 1, Math. Surveys No. 7, Amer. Math. Soc., Providence, R.I., 1961.

3. Mario Petrich, On extensions of semigroups determined by partial homomorphisms, Nederl. Akad. Wetensch. Proc. (A) 69; Indag. Math. 28 (1966), 49-51.

4. R. J. Warne, Extensions of completely 0-simple semigroups by completely 0-simple semigroups, Proc. Amer. Math. Soc. 17 (1966), 524-526. 
Received October 7, 1969. The first author was partially supported by a University of Missouri Research Grant. The second author was partially supported by NSF Grant No. 9618.

The University of Missouri

Columbia, Missouri 



\section{PACIFIC JOURNAL OF MATHEMATICS}

\section{EDITORS}

H. SAmelson

Stanford University

Stanford, California 94305

RICHARd PieRCe

University of Washington

Seattle, Washington 98105

\author{
J. DugundJI \\ Department of Mathematics \\ University of Southern California \\ Los Angeles, California 90007 \\ RICHARD ARENS \\ University of California \\ Los Angeles, California 90024
}

ASSOCIATE EDITORS
E. F. BECKENBACH
B. H. NeumanN
F. WOLF
K. YosHIDA

\section{SUPPORTING INSTITUTIONS}

UNIVERSITY OF BRITISH COLUMBIA

CALIFORNIA INSTITUTE OF TECHNOLOGY

UNIVERSITY OF CALIFORNIA

MONTANA STATE UNIVERSITY

UNIVERSITY OF NEVADA

NEW MEXICO STATE UNIVERSITY

OREGON STATE UNIVERSITY

UNIVERSITY OF OREGON

OSAKA UNIVERSITY

UNIVERSITY OF SOUTHERN CALIFORNIA
STANFORD UNIVERSITY

UNIVERSITY OF TOKYO

UNIVERSITY OF UTAH

WASHINGTON STATE UNIVERSITY

UNIVERSITY OF WASHINGTON

AMERICAN MATHEMATICAL SOCIETY CHEVRON RESEARCH CORPORATION TRW SYSTEMS

NAVAL WEAPONS CENTER 


\section{Pacific Journal of Mathematics}

\section{Vol. 35, No. $1 \quad$ September, 1970}

B. D. Arendt and C. J. Stuth, On the structure of commutative periodic semigroups ..................................... 1

B. D. Arendt and C. J. Stuth, On partial homomorphisms of semigroups .... 7

Leonard Asimow, Extensions of continuous affine functions ............ 11

Claude Elias Billigheimer, Regular boundary problems for a five-term recurrence relation ................................... 23

Edwin Ogilvie Buchman and F. A. Valentine, A characterization of the

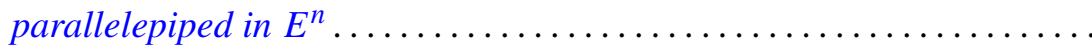
53

Victor P. Camillo, A note on commutative injective rings ............ 59

Larry Jean Cummings, Decomposable symmetric tensors ............. 65

J. E. H. Elliott, On matrices with a restricted number of diagonal values ... 79

Garth Ian Gaudry, Bad behavior and inclusion results for multipliers of type

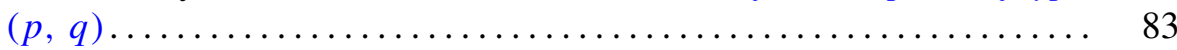

Frances F. Gulick, Derivations and actions .................. 95

Langdon Frank Harris, On subgroups of prime power index . . . . . . . . 117

Jutta Hausen, The hypo residuum of the automorphism group of an abelian

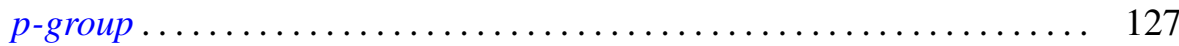

R. Hrycay, Noncontinuous multifuctions . ................... 141

A. Jeanne LaDuke, On a certain generalization of $p$ spaces ............ 155

Marion-Josephine Lim, Rank preservers of skew-symmetric matrices...... 169

John Hathway Lindsey, II, On a six dimensional projective representation of the Hall-Janko group ................................... 175

Roger McCann, Transversally perturbed planar dynamical systems . . . . . 187

Theodore Windle Palmer, Real $C^{*}$-algebras ................... 195

Don David Porter, Symplectic bordism, Stiefel-Whitney numbers, and a

Novikov resolution ....................................... 205

Tilak Raj Prabhakar, On a set of polynomials suggested by Laguerre

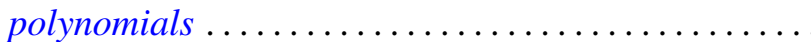

B. L. S. Prakasa Rao, Infinitely divisible characteristic functionals on locally convex topological vector spaces...................

John Robert Reay, Caratheodory theorems in convex product structures ...

Allan M. Sinclair, Eigenvalues in the boundary of the numerical range. .

David R. Stone, Torsion-free and divisible modules over matrix rings ....

William Jennings Wickless, A characterization of the nil radical of a

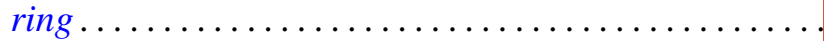

